\title{
ABSORÇÃO DE N, P, K, Ca, Mg e S PELO ARROZ IRRIGADO INFLUENCIADA PELA ADUBAÇÃO NITROGENADA
}

\author{
$\mathrm{N}, \mathrm{P}, \mathrm{K}, \mathrm{Ca}, \mathrm{Mg}$ and $\mathrm{S}$ absorption influenced by nitrogen fertilizing in irrigated rice
}

Moizés de Sousa Reis ${ }^{1}$, Antônio Alves Soares², Plínio César Soares³, Vanda Maria de Oliveira Cornélio ${ }^{4}$

\begin{abstract}
RESUMO
Considerando que ainda não existe um método capaz de avaliar satisfatoriamente a disponibilidade de nitrogênio no solo para as plantas, não sendo possível traçar uma curva de calibração para esse elemento, torna-se necessário trabalhos de pesquisa para estabelecer curvas de resposta em relação a várias doses de nitrogênio, bem como avaliar a resposta de diferentes cultivares. Dessa forma, foi conduzido um experimento em casa-de-vegetação, no Departamento de Ciência do Solo, da Universidade Federal de Lavras, com o objetivo de avaliar o efeito de doses de nitrogênio sobre a produtividade de grãos e a quantidade absorvida e exportada de macronutrientes (N, P, K, Ca, Mg e S) por três cultivares de arroz irrigado. O delineamento experimental utilizado foi o inteiramente casualizado, em esquema fatorial 5 x 3 com quatro repetições. Os fatores constituíram-se de três cultivares de arroz irrigado (Capivari, Inca e Sapucaí) e de cinco doses de nitrogênio $\left(0,100,200,400\right.$ e $800 \mathrm{mg} \mathrm{de} \mathrm{N.kg}{ }^{-1}$ de solo). O nitrogênio foi aplicado na forma de uréia, parcelado em três vezes: 10, 30 e 50 dias após a emergência, nas proporções de $30 \%, 30 \%$ e $40 \%$ da dose total, respectivamente. Houve resposta das cultivares à adubação nitrogenada, com a cultivar Capivari apresentando maior absorção de macronutrientes do que a Inca e a Sapucaí. As cultivares responderam de modo diferencial às doses crescentes de nitrogênio para produtividade de grãos, sendo que a dose máxima utilizada (800 mg de N. $\mathrm{kg}^{-1}$ de solo) não foi suficiente para a Capivari atingir a produtividade máxima. A Capivari foi a mais produtiva das cultivares estudadas, indicando ser mais eficiente na utilização de nitrogênio, enquanto a Sapucaí foi a menos eficiente no aproveitamento desse elemento.
\end{abstract}

Termos para indexação: Cultivares, arroz irrigado, macronutrientes, fertilização.

\begin{abstract}
Taking in account that, there is no available method to adequately evaluate the soil nitrogen availability for plants, there is no way to trace calibration curve for this element, therefore, there is a research needs to establish answer curves in relation to nitrogen rates, as well as, to evaluate different cultivar responses. One experiment in greenhouse conditions was conducted at Soil Science Department of the Federal University of Lavras to evaluate the nitrogen rate effects on grain yield and to estimate the macronutrients $(\mathrm{N}, \mathrm{P}, \mathrm{K}, \mathrm{Ca}, \mathrm{Mg}$ and $\mathrm{S}$ ) absorption and exportation by three irrigated rice cultivars. A completely randomized design with four replicates in factorial arrangement ( 5 by 3 ) using 3 irrigated rice cultivars, (Capivari, Inca e Sapucaí) and 5 nitrogen rates (O, 1OO, $2 \mathrm{OO}, 4 \mathrm{OO}$ e $800 \mathrm{mg}$ of $\mathrm{N}$. kg-1 of soil) as factors were used. Nitrogen rates, in urea form, were applied in three times at 10, 30 and 50 days after emerging using $30 \%, 30 \%$ and $40 \%$ of the total rate, respectively. Capivari presented greater nitrogen absorption than Inca and Sapucaí rice cultivars. Differential grain yield rate responses were presented by cultivars, and $800 \mathrm{mg} \mathrm{of} \mathrm{N}$. kg- ${ }^{1}$ of soil was not enough for Capivari to reach its maximum yield. Capivari rice cultivar had the greatest yield among all cultivars, suggesting it is more efficient in nitrogen utilization, while the Sapucaí was the lesser efficient in nitrogen use.
\end{abstract}

Index terms: Nutrient absorption, irrigated rice cultivars.

(Recebido para publicação em 5 de maio de 2004 e aprovado em 4 de maio de 2005)

\section{INTRODUÇÃO}

O nitrogênio é de fundamental importância na cultura do arroz irrigado, pois promove um melhor desenvolvimento da planta, aumentando a produção de palha, número de panículas por unidade de área e desempenhando papel importante na formação de órgãos reprodutivos e dos grãos. Dentre vários fatores que afetam a utilização do nitrogênio, merece atenção especial a cultivar utilizada. Fageria \& Barbosa Filho (1982) evidenciam diferenças entre as cultivares de arroz irrigado.
Thakur (1993) também verificou que cultivares de arroz se comportaram de modo diferencial à aplicação de nitrogênio para produtividade de grãos.

O nitrogênio é de fundamental importância na cultura do arroz irrigado, pois promove um melhor desenvolvimento da planta, aumentando a produção de palha, número de panículas por unidade de área e desempenhando papel importante na formação de órgãos reprodutivos e dos grãos. Dentre vários fatores que afetam a utilização do nitrogênio, merece atenção especial a cultivar utilizada. Fageria \& Barbosa Filho (1982)

\footnotetext{
${ }^{1}$ Engenheiro Agrônomo, D.Sc., Pesquisador EPAMIG-CTSM - Caixa Postal 176 - 37200-000 - Lavras, MG - moises@epamig.ufla.br ${ }^{2}$ Engenheiro Agrônomo, D.Sc.,Professor da Universidade Federal de Lavras/UFLA - Caixa Postal 3037-37200-000 - Lavras, MG - aasoares@ufla.br ${ }^{3}$ Engenheiro Agrônomo, D.Sc., Pesquisador EPAMIG-CTZM - Caixa Postal 216 - 36570-000 - Viçosa, MG - plinio@mail.ufv.br

${ }^{4}$ Engenheiro Agrônomo, D.Sc., Pesquisador EPAMIG-CTSM - Caixa Postal 176 - 37200-000 - Lavras, MG - vanda@epamig.ufla.br
} 
evidenciam diferenças entre as cultivares de arroz irrigado. Thakur (1993) também verificou que cultivares de arroz se comportaram de modo diferencial à aplicação de nitrogênio para produtividade de grãos.

As diferenças encontradas na resposta a nutrientes podem ser explicadas por mecanismos fisiológicos como diferentes taxas de absorção e translocação e diferenças morfológicas no sistema radicular (MALAVOLTA \& FORNASIERI FILHO, 1983). Nowick \& Hoffpauir (1984) declaram que duas áreas nas quais a eficiência de utilização de nitrogênio pode diferir são a absorção e remobilização. Apontam também que as diferenças varietais podem incluir estrutura da raiz, potencial de oxidação da raiz ou sistema N-redutase. De acordo com Soares et al. (1994), a obtenção de cultivares mais eficientes na absorção e translocação de nutrientes terá prioridade nos programas de melhoramento, uma vez que mais solos pobres são incorporados ao processo produtivo.

A absorção de nutrientes pelas plantas é influenciada pelos fatores externos e internos inerentes à própria planta. A interação entre íons é um assunto bastante estudado, por ser um fator importante no aproveitamento de fertilizantes pelas plantas (MALAVOLTA, 1980). O nitrogênio e o fósforo têm uma relação muito estreita com a produção de grãos, que atinge o máximo quando a relação $\mathrm{N}$ absorvido/P absorvido é de 5/1 (OLIVEIRA et al., 1994). A adição de nitrogênio favorece a utilização do fósforo, possivelmente, por promover melhor desenvolvimento radicular. No caso do potássio, há efeito antagônico do nitrogênio quando fornecido na forma amoniacal. $\mathrm{O}$ antagonismo seria devido à semelhança química entre os íons $\mathrm{NH}_{4}^{+} \mathrm{e} \mathrm{K}^{+}$.

Os teores de nitrogênio e enxofre nas plantas estão fortemente relacionados, sendo que a relação $\mathrm{N}$ total/S total tem sido utilizada como indicador do nível de enxofre. Wallihan \& Sharpless (1974) determinaram, para o arroz, a relação 17/1, referindo que valores superiores poderiam causar deficiência de enxofre, com conseqüente redução do teor de proteína e da produção de grãos. Com relação ao cálcio, altas concentrações de nitrogênio na forma amoniacal têm efeito negativo na sua absorção, devido à competição pelos sítios de troca.

Considerando que ainda não existe um método capaz de avaliar satisfatoriamente a disponibilidade de nitrogênio no solo para as plantas, devido a maior parte desse elemento se encontrar sob a forma orgânica e, como a forma nítrica está sujeita a lixiviação, imobilização e denitrificação, não sendo possível traçar uma curva de calibração, torna-se necessário trabalhos de pesquisa para estabelecer curvas de resposta em relação à várias doses de nitrogênio (BARBOSA FILHO, 1987), bem como avaliar a resposta de diferentes cultivares a esse elemento.

O presente trabalho teve como objetivo avaliar o efeito de doses de nitrogênio sobre a produtividade de grãos e a quantidade absorvida e exportada de macronutrientes (N, P, K, Ca, Mg e S) por três cultivares de arroz irrigado (Inca, Capivari e Sapucaí).

\section{MATERIALEMÉTODOS}

O experimento foi conduzido em casa-de-vegetação, na Universidade Federal de Lavras, Departamento de Ciência do Solo. Cinco kg de terra, coletada em área da Fazenda Experimental da Epamig de Lambari-MG, foram transferidos para vaso plástico com capacidade para 5 litros. O solo é classificado como Gley Pouco Húmico. Antes da instalação do experimento, realizou-se a calagem (em torno de 30 dias) correspondente a 2,2 t.ha ${ }^{-1}$ de calcário e adubação de correção, nas quantidades de 100, 50, 0,5, 5,0 e 1,5 mg. $\mathrm{kg}^{-1}$ de solo de P, K, B, Zn e Cu, respectivamente. À exceção do nitrogênio, os nutrientes foram misturados ao solo antes do enchimento dos vasos. O delineamento experimental utilizado foi o inteiramente casualizado, em esquema fatorial 5 x 3 , com quatro repetições. Os fatores constituíram-se de três cultivares de arroz irrigado (Capivari, Inca e Sapucaí) e de cinco doses de nitrogênio $\left(0,100,200,400\right.$ e $800 \mathrm{mg}$ de N.Kg ${ }^{-1}$ de solo), utilizando-se como fonte a uréia. Semearam-se oito sementes.vaso ${ }^{-1} \mathrm{e}$ após o estabelecimento das plantas, procedeu-se ao desbaste, deixando duas plântulas.vaso ${ }^{-1}$. A adubação nitrogenada foi realizada em três vezes durante o ciclo das plantas, sendo a primeira aos 10 , a segunda aos 30 e a terceira aos 50 dias após a emergência das plântulas, nas proporções de $30 \%, 30 \%$ e $40 \%$ da dose total, respectivamente. O potássio também foi aplicado em cobertura em todos os vasos, na dosagem de $75 \mathrm{mg} \cdot \mathrm{kg}^{-1}$ de solo ( $25 \mathrm{mg} \cdot \mathrm{kg}^{-1}$ de solo em cada parcelamento), nas mesmas épocas em que foi aplicado o nitrogênio. A irrigação foi feita com água desmineralizada, mantendo-se uma lâmina d'água de $5 \mathrm{~cm}$ até a colheita.

Foram avaliadas as seguintes características: absorção de macronutrientes pela parte aérea (palha + grãos) e exportação pelos grãos (porcentagem do total absorvido pela parte aérea). As amostras após secagem em estufa a $60^{\circ} \mathrm{C}$ por $24 \mathrm{~h}$ foram moídas e pesadas para determinação da matéria seca. A quantidade de nutrientes na parte aérea e nos grãos foi obtida pelo produto da matéria seca da parte aérea e dos grãos pela porcentagem de cada 
elemento. Os teores de nutrientes foram analisados no laboratório de nutrição de plantas, Departamento de Ciência do solo da UFLA, de acordo com os métodos descritos por Malavolta et al. (1997). A determinação de N foi feita pelo método semi-micro-Kjeldahl, do $\mathrm{P}$ por colorometria pelo método metavanadato, $\mathrm{Ca}$ e $\mathrm{Mg}$ por espectrofotometria de absorção atômica e o $\mathrm{K}$ e o $\mathrm{S}$ por fotometria de chama e pelo método turbitimétrico, respectivamente. A eficiência de utilização de nitrogênio foi calculada pela da relação entre a produção de grãos e a quantidade de nitrogênio contida na parte aérea.

As análises de variância foram efetuadas para cada característica avaliada. Para comparação das cultivares quanto a produtividade de grãos e eficiência de utilização de nitrogênio, foi empregado o teste de médias (Tukey$0,05)$ e para respostas às dosagens de nitrogênio, utilizouse análise de regressão, aceitando-se até o $2^{\circ}$ grau como significativo. Pelas equações de regressão obtidas para produtividade de grãos, estimaram-se as doses de nitrogênio correspondentes aos máximos rendimentos das cultivares testadas.

\section{RESULTADOS E DISCUSSÃO}

\section{Absorção e exportação de nutrientes}

A absorção de N, P, K, Ca, Mg e S foi influenciada pelas doses de $\mathrm{N}$ e cultivares, havendo significância da interação entre os fatores para absorção somente para o nitrogênio (Fig.1). A interação entre cultivares e doses de nitrogênio, para quantidade de nitrogênio absorvida pela parte aérea, foi significativa indicando comportamento diferencial das cultivares. A resposta das três cultivares à aplicação de nitrogênio se ajustou a um modelo de regressão linear. A cultivar Sapucaí absorveu menor quantidade de nitrogênio do que a Inca e Capivari, o que provavelmente está associado à menor produtividade de grãos dessa cultivar, confirmando assim uma menor eficiência na absorção e utilização do nitrogênio.

Pode-se fazer ainda uma comparação entre a quantidade de nitrogênio aplicado ao solo e a quantidade de nitrogênio absorvida pela parte aérea (palha + grãos) para as três cultivares de arroz. À medida que se aumentaram as doses de nitrogênio, as quantidades de nitrogênio absorvidas reduziram proporcionalmente, apesar de terem aumentado em valores absolutos. A relação nitrogênio absorvido/nitrogênio aplicado foi de 1,19; 0,97; 0,79 e 0,68, para as dosagens de 100, 200, 400 e 800 mg. $\mathrm{kg}^{-1}$ de solo, respectivamente. Logo, as plantas utilizaram mais o nitrogênio do solo quando doses menores do elemento foram aplicadas. Por outro lado, a utilização de nitrogênio do solo pelas plantas pode ter sido também alta mesmo em altas doses de nitrogênio. A decomposição da matéria orgânica do solo estudado, que é considerada alta (3,5\%), pode ter liberado mais nitrogênio para as plantas com a aplicação de altas doses de nitrogênio. Isto pode ser uma possível explicação para as altas relações $\mathrm{N}$ absorvido/ $\mathrm{N}$ aplicado, que foi de no mínimo $68 \%$ para a dosagem máxima aplicada. Fageria (1984), entretanto, afirma que a absorção do nitrogênio aplicado na cultura do arroz pode chegar a 60-65\%, utilizando melhor prática agronômica, em condições controladas.

Com relação aos demais nutrientes, observa-se que as três cultivares responderam ao aumento de $\mathrm{N}$ para a absorção de $\mathrm{P}$, com a cultivar Capivari apresentando teores maiores do que a Inca e a Sapucaí, sendo que estas duas cultivares não diferiram estatisticamente entre si, em todos os níveis de $\mathrm{N}$ testados. A absorção máxima, na média das cultivares, foi atingida na dose de 533 e 463 mg de N.kg-1 de solo para $\mathrm{P}$ e $\mathrm{K}$, respectivamente. Para o $\mathrm{Ca}$ e o $\mathrm{S}$, a absorção pela cultivar Capivari foi estatisticamente igual a Inca, porém superior a Sapucaí. A absorção máxima de Ca e $\mathrm{S}$ para as três cultivares foi atingida nas doses de 753 e 734 mg de N. $\mathrm{kg}^{-1}$ de solo, respectivamente. Com relação ao $\mathrm{Mg}$, observa-se que o comportamento das cultivares foi um pouco diferente do apresentado para os outros macronutrientes, em que a Capivari foi superior a Inca que, por sua vez, foi superior a Sapucaí, em todos os níveis de $\mathrm{N}$, com as cultivares atingindo a absorção máxima na dose de 649 mg de N.kg-1 de solo.

A maior absorção de nutrientes pela cultivar Capivari, principalmente em relação a Sapucaí, pode explicar a maior produtividade de grãos dessa cultivar, indicando que a mesma é mais eficiente na absorção e utilização de nutrientes do que as outras duas cultivares.

Com relação a exportação de nutrientes (Tabela 1), as cultivares não diferiram estatisticamente em relação ao percentual de nitrogênio exportado. Os resultados obtidos demonstraram que, na média das três cultivares e das cinco dosagens de nitrogênio, $60 \%$ do nitrogênio total da parte aérea foi exportado pelos grãos, o que reflete a translocação da maior parte do nitrogênio para os grãos. Estes resultados estão bem próximos dos encontrados por Lopes et al. (1993) que verificaram valores de 60 e 62\%, respectivamente, em seus experimentos. Os resultados, no entanto, diferem um pouco dos relatados por Malavolta (1979) em que os grãos, no final do ciclo, contém cerca de 


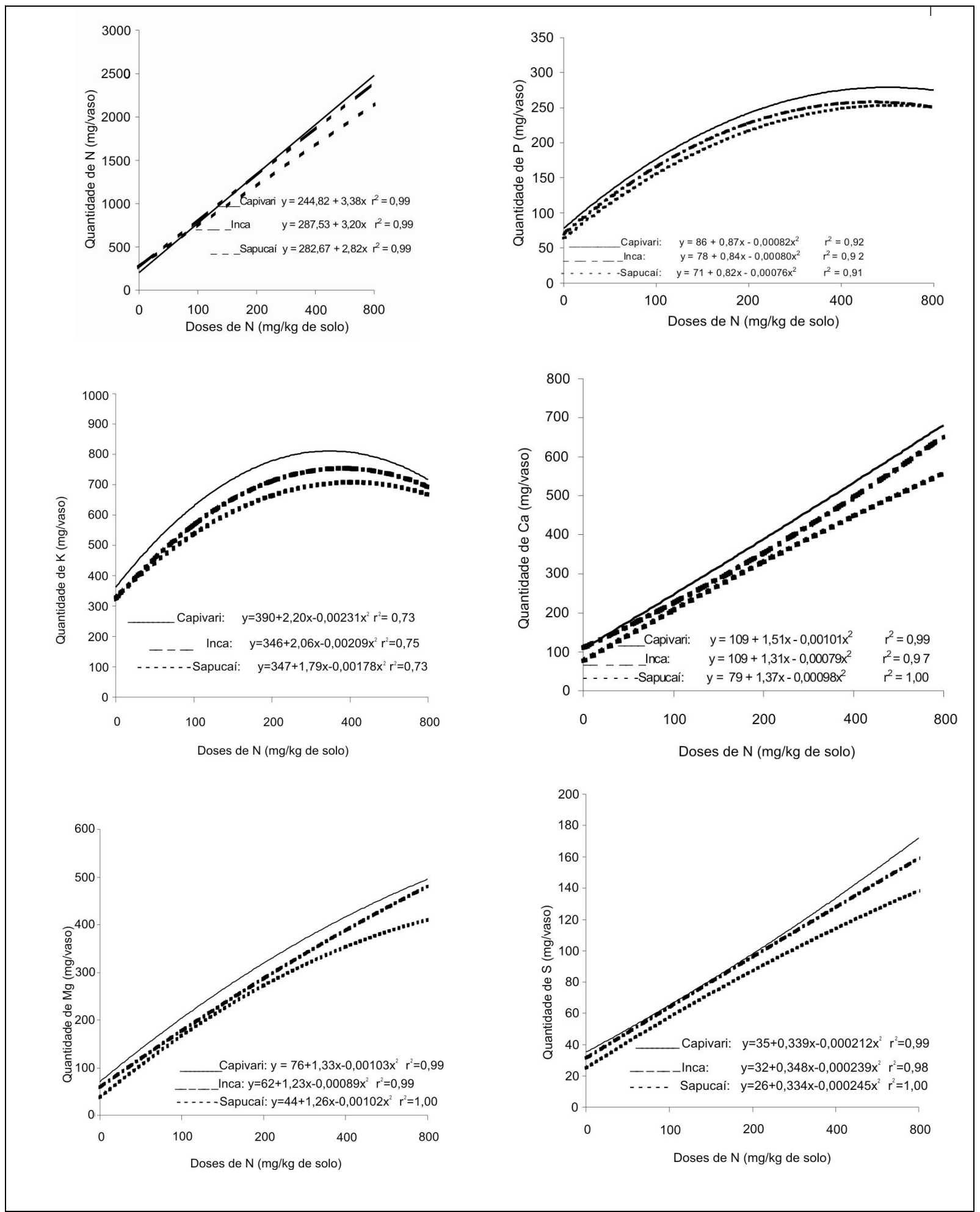

FIGURA 1 - Efeito de doses de N na absorção de N, P, K, Ca, Mg e S por três cultivares de arroz irrigado. UFLA, 2004.

Ciênc. agrotec., Lavras, v. 29, n. 4, p. 707 -713, jul./ago., 2005 
TABELA 1 - Exportação de macronutrientes pelos grãos, na média de cinco dosagens de nitrogênio, por três cultivares de arroz irrigado. UFLA (2004).

\begin{tabular}{|c|c|c|c|c|c|c|}
\hline \multicolumn{7}{|c|}{$\%$ exportado } \\
\hline & $\mathbf{N}$ & $\mathbf{P}$ & $\mathbf{K}$ & $\mathbf{C a}$ & Mg & $\mathbf{S}$ \\
\hline Capivari & $59 a$ & $58 \mathrm{a}$ & $16 \mathrm{a}$ & $16 \mathrm{c}$ & $21 \mathrm{~b}$ & $53 \mathrm{a}$ \\
\hline Inca & $59 a$ & $61 \mathrm{a}$ & $16 \mathrm{a}$ & $23 \mathrm{a}$ & $24 \mathrm{a}$ & $47 \mathrm{~b}$ \\
\hline Sapucaí & $61 \mathrm{a}$ & $59 \mathrm{a}$ & $14 \mathrm{a}$ & $19 \mathrm{~b}$ & $25 \mathrm{a}$ & $41 \mathrm{c}$ \\
\hline Média & 60 & 59 & 15 & 19 & 23 & 47 \\
\hline
\end{tabular}

${ }^{1}$ Médias seguidas pela mesma letra não diferem estatisticamente (Tukey - 0,05).

\section{Produtividade de grãos e Eficiência de utilização de nitrogênio}

Na Figura 2 observa-se a produtividade de grãos das cultivares Capivari, Inca e Sapucaí sob as cinco dosagens de nitrogênio. Nota-se que a produtividade de grãos aumentou com o incremento das doses de nitrogênio para todas as cultivares, observando inclusive interação significativa entre cultivares e doses de nitrogênio. Thakur (1993) também verificou interação significativa entre cultivares e doses de nitrogênio para rendimento de grãos, confirmando que diferentes cultivares de arroz respondem de modo peculiar às diferentes doses de nitrogênio. A resposta das cultivares ajustou-se a um modelo de regressão quadrática, mas a produtividade máxima estimada da Capivari não foi atingida com a dosagem máxima de nitrogênio aplicado ( $800 \mathrm{mg}$ de N. $\mathrm{kg}^{-1}$ de solo). Pela equação de regressão obtida para esta cultivar estimou-se a dosagem de nitrogênio que atingiria a máxima produtividade de grãos, a qual foi de $1.063 \mathrm{mg}$ de N.kg-1 de solo. Apesar de não ter diferenciado estatisticamente da Inca, a cultivar Capivari apresenta maior potencial para produção de grãos tendo em vista que a mesma não atingiu a máxima produtividade de grãos para a dose de $\mathrm{N}$ utilizada. Com relação ao comportamento das cultivares Inca e Sapucaí, observa-se que foi atingida a máxima produtividade de grãos mas depois diminuiu com o aumento das doses de nitrogênio. As máximas produtividades de grãos estimadas, das cultivares Inca e Sapucaí, foram obtidas com as doses de 746 e 584 mg de N. $\mathrm{kg}^{-1}$ de solo, respectivamente.

Pela Tabela 2 verifica-se a eficiência de utilização de nitrogênio das três cultivares sob as cinco dosagens de nitrogênio. Nota-se que a eficiência de utilização foi reduzida à medida que se aumentaram as doses de nitrogênio, passando de um valor médio entre cultivares de 67,2 quando não se aplicou nitrogênio, para 29,7 com a aplicação da dosagem máxima de nitrogênio. Houve também diferença significativa entre as cultivares para eficiência de utilização de nitrogênio. Na média das cinco dosagens de nitrogênio, os valores de eficiência de utilização foram de 53,8 e 52,6, para as cultivares Capivari e Inca, respectivamente. A cultivar Sapucaí apresentou uma eficiência de utilização de 47,5, sendo portanto, menor que das cultivares Capivari e Inca, indicando que a Sapucaí é menos eficiente na utilização de nitrogênio. Os resultados estão de acordo com Fageria \& Barbosa Filho (1982) que evidenciam diferenças na utilização de nitrogênio entre as cultivares de arroz irrigado.

A eficiência de uso do nitrogênio aplicado pode ser medida ou calculada pela relação produção de grãos/ quantidade de $\mathrm{N}$ aplicado ao solo. Esta relação, na média das cinco dosagens de nitrogênio, foi de 36,2; 34,5 e 28,8, para as cultivares Capivari, Inca e Sapucaí, respectivamente. Observe que a cultivar Sapucaí foi menos eficiente na utilização do nitrogênio aplicado para produção de grãos.

A relação produção de grãos/quantidade de $\mathrm{N}$ aplicado, na média das três cultivares, foi de 33,2. Este valor está acima dos relatados por Leon \& Arregocés (1985), em que vários trabalhos mostram que a média mundial de aumento de rendimento de grãos, com o uso da adubação nitrogenada, está entre 21 e $24 \mathrm{~kg}$ de grãos por unidade de nitrogênio, apesar de que o incremento em rendimento pode chegar a $41 \mathrm{~kg}$ de arroz. $\mathrm{kg}^{-1}$ de $\mathrm{N}$ aplicado.

Os resultados evidenciam que a cultivar Capivari é superior à Inca e à Sapucaí quanto ao aproveitamento do N. Logo, deverá ser a cultivar preferida para cultivo em ambientes onde há maior disponibilidade desse elemento.

$\mathrm{O}$ maior rendimento de grãos apresentado pela Capivari em experimentos de campo (SOARES et al., 1995) e a maior resposta à aplicação de nitrogênio, em relação a Inca e Sapucaí, torna essa cultivar a mais indicada para plantio quando se utiliza adubação nitrogenada pesada, bem como em condições edafoclimáticas favoráveis. 


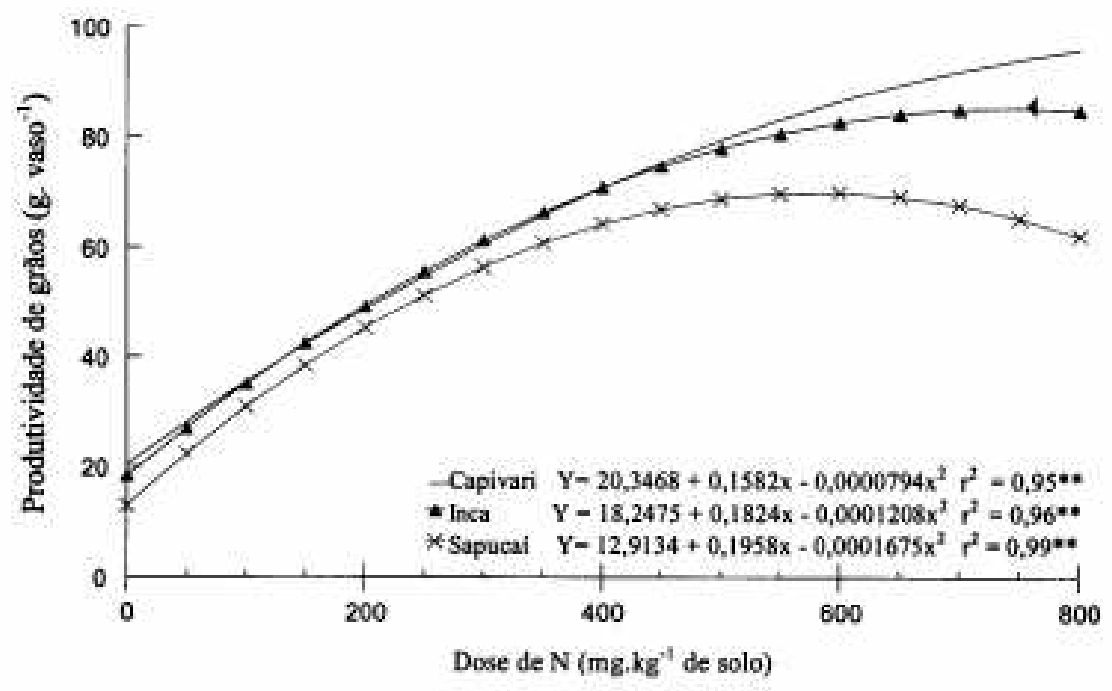

FIGURA 2 - Produtividade de grãos (g.vaso-1) de três cultivares de arroz irrigado em função de cinco dosagens de nitrogênio. UFLA (2004).

TABELA 2 - Eficiência de utilização de nitrogênio $(E)^{1}$ de três cultivares de arroz irrigado sob cinco dosagens de nitrogênio. UFLA (2004).

\begin{tabular}{lcccccc}
\hline \multirow{2}{*}{ Cultivar } & \multicolumn{7}{c}{ Doses de N (mg.kg } & de solo) & \multirow{2}{*}{ Média $^{\mathbf{2}}$} \\
\cline { 2 - 6 } & $\mathbf{0}$ & $\mathbf{1 0 0}$ & $\mathbf{2 0 0}$ & $\mathbf{4 0 0}$ & $\mathbf{8 0 0}$ & \\
\hline Capivari & 66,8 & 73,0 & 56,3 & 39,6 & 33,1 & $53,8 \mathrm{a}$ \\
Inca & 74,5 & 61,7 & 55,8 & 40,4 & 30,6 & $52,6 \mathrm{a}$ \\
Sapucaí & 60,4 & 60,1 & 51,2 & 40,7 & 25,3 & $47,5 \mathrm{~b}$ \\
\hline Média & 67,2 & 64,9 & 54,4 & 40,2 & 29,7 & 51,3 \\
\hline
\end{tabular}

${ }^{1} \mathrm{E}=$ Produção de grãos $\left(\right.$ g.vaso $\left.{ }^{-1}\right) /$ Quantidade de $\mathrm{N}$ da parte aérea (palha + grãos) em g.vaso ${ }^{-1}$.

${ }^{2}$ Médias seguidas pela mesma letra não diferem estatisticamente (Tukey - 0,05).

A eficiência de utilização de nitrogênio (produção de grãos/quantidade de nitrogênio absorvida pela parte aérea), na média das três cultivares, foi de 51,3, estando de acordo com a afirmação de Yoshida (1981) de que a eficiência de uso de nitrogênio nos trópicos é de $50 \mathrm{~kg}$ de arroz. $\mathrm{kg}^{-1}$ de nitrogênio.

A eficiência de uso do nitrogênio aplicado pode ser medida ou calculada pela relação produção de grãos/ quantidade de $\mathrm{N}$ aplicado ao solo. Esta relação, na média das cinco dosagens de nitrogênio, foi de 36,2; 34,5 e 28,8, para as cultivares Capivari, Inca e Sapucaí, respectivamente. Observe que a cultivar Sapucaí foi menos eficiente na utilização do nitrogênio aplicado para produção de grãos.

A relação produção de grãos/quantidade de $\mathrm{N}$ aplicado, na média das três cultivares, foi de 33,2. Este valor está acima dos relatados por Leon \& Arregocés (1985), em que vários trabalhos mostram que a média mundial de aumento de rendimento de grãos, com o uso da adubação nitrogenada, está entre 21 e $24 \mathrm{~kg}$ de grãos por unidade de nitrogênio, apesar de que o incremento em rendimento pode chegar a $41 \mathrm{~kg}$ de arroz. $\mathrm{kg}^{-1}$ de $\mathrm{N}$ aplicado.

Os resultados evidenciam que a cultivar Capivari é superior à Inca e à Sapucaí quanto ao aproveitamento do N. Logo, deverá ser a cultivar preferida para cultivo em 
ambientes onde há maior disponibilidade desse elemento.

O maior rendimento de grãos apresentado pela Capivari em experimentos de campo (SOARES et al., 1995) e a maior resposta à aplicação de nitrogênio, em relação a Inca e Sapucaí, torna essa cultivar a mais indicada para plantio quando se utiliza adubação nitrogenada pesada, bem como em condições edafoclimáticas favoráveis.

\section{CONCLUSÕES}

Houve resposta das cultivares à adubação nitrogenada para a absorção de macronutrientes.

As cultivares Capivari, Inca e Sapucaí mostraramse eficientes quanto a utilização de nitrogênio, todavia, a Sapucaí não mostrou o mesmo desempenho das outras duas, sendo portanto menos responsiva.

As cultivares responderam de modo diferencial às doses crescentes de nitrogênio para produtividade de grãos, sendo que a dose máxima utilizada ( $800 \mathrm{mg}$ de N. $\mathrm{kg}^{-1}$ de solo) não foi suficiente para a Capivari atingir a produtividade máxima.

\section{REFERÊNCIAS BIBLIOGRÁFICAS}

BARBOSA FILHO, M. P. Nutrição e adubação do arroz: sequeiro e irrigado. Piracicaba: Associação Brasileira para Pesquisa de Potassa e Fosfato, 1987. 129 p. (Boletim técnico, 9).

FAGERIA, N. K. Adubação e nutrição mineral da cultura do arroz. Goiânia: EMBRAPA/CNPAF, 1984. 341 p.

FAGERIA, N. K.; BARBOSA FILHO, M. P. Avaliação preliminar de cultivares de arroz irrigado para maior eficiência de utilização de nitrogênio. Pesquisa Agropecuária Brasileira, Brasília, v. 17, n. 12, p. 17091712, dez. 1982.

LEON, L. A.; ARREGOCÉS, O. Factores que afectam la respuesta a la fertilization nitrogenadadel arroz. In: CENTRO INTERNACIONAL DE AGRICULTURA TROPICAL. Arroz: Investigacion y producion. Cali, 1985. p. 307-340.

LOPES, S. I. G.; VOLKWEISS, S. J.; TEDESCO, M. J. Acumulação de matéria seca e absorção de nutrientes pela cultura de arroz irrigado. Lavoura Arrozeira, Porto Alegre, v. 46, n. 411, p. 3-7, nov./dez. 1993.

MALAVOLTA, E. Nutrição mineral e adubação do arroz de sequeiro. 2. ed. Piracicaba: ULTRAFÉRTIL, 1979.40 p.
MALAVOLTA, E. Elementos de nutrição mineral de plantas. São Paulo: Agronômica Ceres, 1980. 251 p.

MALAVOLTA, E.; FORNASIERI FILHO, D. Nutrição mineral da cultura do arroz. In: FERREIRA, M. E.; YAMADA, T.; MALAVOLTA, E. Cultura do arroz de sequeiro: fatores afetando a produtividade. Piracicaba: Instituto da Potassa e Fosfato, 1983. p. 95-140.

MALAVOLTA, E.; VITTI, G. C.; OLIVEIRA, S. A. Avaliação do estado nutricional das plantas: princípios e aplicações. 2. ed. Piracicaba: POTAFOS, 1997.319p.

NOWICK, E. M.; HOFFPAUIR, H. Varietal diferences in nitrogen uptake at two $\mathrm{N}$ levels and three growth stages. In: RICE RESEARCH STATION. Annual progress report. Louisiana: Crowley, 1984. p. 51-55.

OLIVEIRA, P. S. R.; CARVALHO, J. G; CARVALHO, G. J.; SOARES, A. A.; ALLEONI, L. R. A. Efeito da adubação nitrogenada na absorção, translocação e exportação de $\mathrm{P}$, $\mathrm{K}, \mathrm{Ca}, \mathrm{Mg}$ e S por quatro cultivares e uma linhagem de arroz (Oryza sativa L.). Unimar Ciências, Marília, v. 3, p. 30-40, 1994.

SOARES, A. A.; CARVALHO, J. G.; CARVALHO, G. J.; FONSECA, J. R.; OLIVEIRA, P. S. R. Diferenças varietais na absorção, translocação e exportação de nitrogênio em arroz de sequeiro. Ciência e Prática, Lavras, v. 18, n. 3, p. 248-257, jul./set. 1994.

SOARES,A.A.; REIS, M.S.; CORNÉLIO, V.M.O.; SOARES, P. C. Urucuia, Sapucaí e Capivari: novos cultivares de arroz irrigado para o estado de Minas Gerais. Revista Ceres, Viçosa, v. 42, n. 240, p. 225-232, out. 1995.

THAKUR, R. B. Performance of summer rice to varying levels of nitrogen. Indian Journal Agronomy, New Delhi, v. 38, n. 2, p. 187-190, June, 1993.

WALLIHAN, E. F.; SHARPLESS, R. G. Effect of supply on the optimum concentration of nitrogen in leaves of the rice plant. Soil Science, Baltimore, v. 118, n. 5, p. 304307, 1974.

YOSHIDA, S. Fundamentals of rice crop science. Los Banos: International Rice Research Institute, 1981. $269 \mathrm{p}$. 